\title{
VALUATION OF HOUSING INDEX DERIVATIVES
}

\author{
MELANIE CAO* \\ JASON WEI
}

This study analyzes the valuation of housing index derivatives traded on the Chicago Mercantile Exchange (CME). Specifically, to circumvent the nontradability of housing indices, we propose and implement an equilibrium valuation framework. Assuming a mean-reverting aggregate dividend process and a utility function characterized by constant relative risk aversion, we show that the value of a housing index derivative depends only on parameters characterizing the underlying housing index, the endogenized interest rate and their correlation. We also analytically and numerically examine risk premiums for the CME futures and options and obtain three important findings. First, risk premiums are significant for all contracts with maturities longer than one year. Second, the expected growth rate of the underlying index is the key determinant for risk premiums. Third, risk premiums can be positive or negative, depending on whether the expected growth rate of the underlying index is higher or lower than the risk-free yield-to-maturity. (C) 2009 Wiley Periodicals, Inc. Jrl Fut Mark 30:660-688, 2010

\begin{abstract}
We thank an anonymous referee, the Editor, Bob Webb, Alexander David and Shu Yan for their constructive comments and suggestions. This paper has also benefited from comments made by conference participants at the 2009 China International Conference in Finance and the 2009 Northern Finance Association meeting. We also thank Dan Li for her excellent research assistance. Both authors are grateful to the Social Sciences and Humanities Research Council of Canada for financial support.
\end{abstract}

*Correspondence author, Schulich School of Business, York University, 4700 Keele Street, Toronto, Ontario, Canada M3J 1P3. Tel: 416-736-2100 extn. 33801, Fax: 416-736-5687, e-mail: mcao@schulich.yorku.ca

Received July 2008; Accepted August 2009

- Melanie Cao is at Schulich School of Business, York University, Toronto, Ontario, Canada.

- Jason Wei is at Joseph L. Rotman School of Management, University of Toronto, Toronto, Ontario, Canada. 


\section{INTRODUCTION}

On May 26, 2006, the CME, in collaboration with MarcroMarkets LLC, introduced the first exchange-traded futures and options on housing market indices. The purpose was to offer hedging vehicles for the real estate markets. The contracts are written on 11 SP/CS (Standard and Poor's/Case Shiller) housing indices representing residential real estate markets in Boston, Chicago, Denver, Las Vegas, Los Angeles, Miami, New York, San Diego, San Francisco, Washington DC, and the entire USA. Despite exceptional volatility in residential real estate prices, the trading volume of CME housing derivatives has been low. According to the CME report, the total trading volumes for 2007 and 2008 were only 4,364 and 1,178 , respectively. ${ }^{1}$

This slow development is similar to that of the CME weather derivatives market shortly after its inception in 1997. The underlying variables for the CME weather contracts are nontradable, temperature indices. The nontradability of the underlying posed valuation challenges. Not surprisingly, in the early years, reliable valuation models were slow in coming and potential market participants stayed on the sidelines for not knowing exactly how the weather derivatives should be valued. The market saw only sporadic trades and the total trading volume was in the range of 2,000-5,000 contracts per year. Subsequently, various valuation models were developed and became available in the public domain. Meantime, there was an increased awareness of weather derivatives in the investment community, especially among hedge funds. As a result, more participants were drawn to the market and the trading volume increased in multifold. For instance, the trading volume of weather derivatives (in number of contracts) on the CME for 2007 and 2008 were 927,461 and 776,397 , respectively, a dramatic increase from the few thousand contracts in the early years. Though still thin in absolute terms, the weather derivatives market did see some impressive growth in the past few years. We attribute the growth, if not entirely, to the advancement of valuation techniques.

The experience with the weather derivatives market suggests that the inactive trading in the housing derivatives market might be due to the lack of valuation models. Here, the valuation challenge lies in the fact that the residential housing market is illiquid and the underlying housing indices are not tradable. The nontradability of housing indices renders the usual risk-neutral valuation technique powerless. Nevertheless, technical challenges do not mean that the market would not catch up, as already demonstrated by the weather derivatives market. In fact, the sheer size of the real estate market offers great potentials: As of 2008, the real estate market in the US was valued at \$20.511 trillion,

\footnotetext{
${ }^{1}$ In fact, there was an across-the-board decrease in trading volume for almost all CME-traded derivatives. The grand total of contracts traded in 2008 was $111,469,604$, in contrast to $119,748,558$ in 2007 . The overall decline in trading activities might be a result of the recent financial downturn.
} 
compared with $\$ 27.35$ trillion for the equity market and \$33.49 trillion for the fixed-income market. ${ }^{2}$ Even hedging demand alone should lead to a sizable housing derivatives market. It is hoped that a better understanding of the valuation principles will stimulate and facilitate more active participation in this emerging market.

This study is aimed at fulfilling the above hope. The objective is twofold. The first is to propose a valuation model that can accommodate the nontradable nature of housing indices. Specifically, we extend Lucas' equilibrium model (Lucas, 1978) by introducing a housing market in addition to the financial and goods markets. We specialize the model by assuming a constant-relative-riskaversion preference, a mean-reverting aggregate dividend process, and a geometric Brownian motion for the housing index. In this framework, the instantaneous risk-free interest rate is endogenous and follows a Vasicek-type mean-reverting process with parameters expressed in terms of the risk-aversion parameter and parameters governing the aggregate dividend process. With the joint processes of the housing index and the risk-free interest rate, we obtain closed-form valuation formulas for housing index derivatives.

The other objective of this study is to study risk premiums arising from the nontradability of housing indices. To this end, we define the risk premium of a housing index derivative as the percentage difference between the equilibrium value and the risk-neutral value of the derivative. The analysis then proceeds in two steps: analytical and numerical. The general, analytical, comparative statics reveal the following insights: (1) the risk premium for a futures contract increases with the maturity, the expected housing index return, its return volatility and the correlation between the housing index and the interest rate, and decreases with the long-run mean of the interest rate; $(2)$ the risk premium for a call increases with the expected housing index return, its return volatility and the correlation between the housing index and the interest rate; (3) the risk premium for a put decreases with the expected housing index return, its return volatility and the correlation between the housing index and the interest rate; and (4) the effects of other model parameters are indeterminate for call and put options.

The numerical analysis is tailored to the CME housing index derivatives. To facilitate the exercise, we first empirically estimate the parameters for the housing index process and the risk-free interest rate for the sample period of 1987-2007. We then calculate the risk premiums for various parameter combinations. Our numerical analysis leads to three important findings. First, risk

\footnotetext{
${ }^{2}$ The real estate market value and the equity market capitalization are retrieved from the Federal Reserve's statistical release Z.1, Table B.100 titled "Balance sheet of Households and nonprofit organizations". The table can be downloaded from http://www.federalreserve.gov/releases/z1/Current/z1r-5.pdf. The bond market value is obtained from the Securities Industry and Financial Markets Association (http://www.sifma.org/ uploadedFiles/Research/Statistics/SIFMA_USBondMarketOut standing.pdf).
} 
premiums are significant for all contracts with longer maturities. Second, the magnitude of risk premiums is large when the underlying housing index exhibits high growth rate. Third, risk premiums can be positive or negative, depending on whether the expected growth rate of the underlying index is higher or lower than the risk-free yield-to-maturity.

The rest of the study is organized as follows. Second section describes CME housing index derivatives and illustrates potential diversification benefits of these contracts for portfolio management. Subsequent section proposes an equilibrium model to value futures and options. Analytical expressions of risk premiums and various comparative statics are derived. Penultimate section conducts numerical analyses of risk premiums for the CME housing index derivatives. Last section concludes the study. Proofs and tables are relegated to the Appendix.

\section{CME HOUSING DERIVATIVES AND THEIR POTENTIAL BENEFITS TO PORTFOLIO MANAGEMENT}

In order to study the valuation of housing derivatives, it is instrumental to understand the contracts traded on the CME. To this end, we first describe specifications of the CME housing index contracts. We then provide some insights into the potential benefits of these contracts in the context of portfolio management.

\section{CME Futures and Options on Housing Indices}

The underlying variables for the CME housing contracts are based on the SP/CS indices that are published by Fiserv CSW Inc. These indices are computed based on the repeated-sales method. ${ }^{3}$ According to the CME, these indices are widely recognized as the most reliable and authoritative measures of residential housing price movements for a variety of purposes, including loan portfolio due diligence, customer retention, loss reserve reviews, market surveillance, mortgage default, loss and replacement analyses. ${ }^{4}$ The SP/CS indices are established at 100 for the base year of 2000 and are updated and released each month at 1:15 p.m. Central Time on the last Tuesday of the month. The monthly housing indices are based on a three-month rolling window. ${ }^{5}$ Take an index released on April 25, 2008 as an example. In this case, the index value would be calculated based on transactions that occurred in February, March,

\footnotetext{
${ }^{3}$ For detailed discussions on the repeated-sales method, please consult Case (1986). In a recent paper, Shiller (2008) outlined the advantages of using the repeated-sales method over the hedonic method.

${ }^{4}$ For further details, please see the CME website: www.cme.com/files/cmehousing_brochure.pdf.

${ }^{5}$ For further details about the SP/CS Indices, please refer to the CME's housing index resource center at www.cme.com/trading/prd/re/housing_OR.html.
} 
TABLE I

Examples of CME Housing Futures and Options

\begin{tabular}{|c|c|c|}
\hline & Futures & Call options on Futures \\
\hline Location & New York & Chicago \\
\hline Contract maturity & $\begin{array}{l}\text { February quarterly cycle of } \\
\text { August } 2009\end{array}$ & $\begin{array}{l}\text { February quarterly cycle of } \\
\text { November } 2009\end{array}$ \\
\hline Tick size & $\begin{array}{l}\$ 250 \text { times the SP/CS } \\
\text { New York index }\end{array}$ & $\begin{array}{l}\$ 250 \text { times the SP/CS } \\
\text { Chicago index }\end{array}$ \\
\hline Futures price & 200 & \\
\hline Strike level & & 155 \\
\hline Settlement date & $\begin{array}{l}\text { One business day after } 25 \text { th } \\
\text { of the contract month }\end{array}$ & $\begin{array}{l}\text { One business day after 25th } \\
\text { of the contract month }\end{array}$ \\
\hline The actual index at maturity & 195 for August 2009 & 165 for November 2009 \\
\hline Payoffs at maturity for a long position & $(195-200) \times 250=-\$ 1,250$ & $\max (165-155,0) \times 250=\$ 2,500$ \\
\hline Payoffs at maturity for a short position & $(200-195) \times 250=\$ 1,250$ & $-\max (165-155,0) \times 250=-\$ 2,500$ \\
\hline
\end{tabular}

and April. By the same token, for the next index value released on May 25, 2008, price information for March, April, and May would be utilized in the index calculation.

The CME has listed futures and options on eleven SP/CS indices. The first ten are for the residential housing markets of the following metropolitan areas: Boston, Chicago, Denver, Las Vegas, Los Angeles, Miami, New York, San Diego, San Francisco, and Washington, DC. The last index is a market-capitalizationweighted composite index for the ten metropolitan areas.

The CME housing index futures are listed with a February quarterly expiration cycle (i.e., February, May, August, and November) and are settled at \$250 times the indices. Table I illustrates the typical elements of a futures contract and an option on a futures contract. In the example, a futures contract is written on the New York housing index. The maturity is August 2009, and the futures price is quoted at 200. The tick size is set at \$250. If the realized New York housing index by the end of August 2009 is 195, then the payoff for a long position will be $\$ 250 \times(195-200)=-\$ 1,250$. For the call option on Chicago futures, the maturity is November 2009, which is the same as that of the underlying futures contract. If the realized Chicago housing index by the end of November 2009 is 165 , then the call payoff for a long position will be $\max (165-155,0) \times$ $250=\$ 2,500$.

To stimulate trading activities, in September 2007, the CME added longer maturities to the existing February quarterly cycles. The longer maturity goes from one year to five years. In addition, on October 29, 2007, the CME introduced futures and options on the S\&P/GRA Commercial Real Estate Indices, complementary to the SP/CS residential housing index futures and options. The S\&P/GRA indices are published as a joint venture between Standard and 
Poor's and Global Real Analytics/Charles Schwab Investment Management. These new products, based on five regional indices and four national propertytype indices, primarily target hedging needs in the commercial real estate market. The five geographic regions include Northeast, Midwest, Mid-Atlantic South, Pacific West, and Desert Mountain West, whereas the four national property types include office, warehouse, apartment, and retail. Our valuation framework in third section cast in the residential setting is equally applicable to the commercial real estate setting.

\section{Potential Benefits of CME Housing Derivatives Contracts to Portfolio Management}

Although housing index derivatives are intended for managing real estate risks, they can be useful diversification vehicles in the context of portfolio management. To make this point, we first construct the efficient frontier using only the risk-free asset, the equity index, and the bond index. We then enlarge the portfolio choice set by including index futures that track the movements of the housing indices. We investigate the extent of return improvement for the same level of risk. The position on the housing index futures is chosen so as to replicate the housing index value. ${ }^{6}$

In this exercise, the three-month T-bill rates, retrieved from www.federal reserve.gov, are used as returns from the risk-free asset; the S\&P 500 index and the Citigroup US Broad Investment Grade (BIG) index, both retrieved from Datastream, are used to represent the US equity and bond markets, respectively ${ }^{7}$ the housing index data are retrieved from www2.standardandpoors.com/ spf/pdf/index/CS_HomePrice_History_042952.xls. As the housing index data is limited to a monthly frequency for the period of January 1987-December 2007, we end up with a final sample size of 252.

Table II presents the summary statistics. Panel A indicates that the riskfree rate is quite volatile during the sample period of 1987-2007. It ranges from a low of $0.72 \%$ to a high of $9.48 \%$. There is very little skewness in the risk-free rate in that the average $(4.44 \%)$ is close to the median $(4.68 \%)$. The bond market has an average return of $7.08 \%$ and a volatility of $4.01 \%$, whereas the equity market has an average return of $8.02 \%$ and a volatility of $14.66 \%$. It is worth noting that the bond market performed much better than the equity market in terms of Sharpe ratio. As for housing indices, the average return ranges from

\footnotetext{
${ }^{6}$ The specific futures position is dictated by the value of a futures contract in (6) and the relationship defined in (10). That is, we can replicate the housing index value by taking $1 / \lambda_{\text {fwd }}$ position in the futures contract and $K e^{-R(t, T)(T-t)} / \lambda_{\text {fwd }}$ in cash.

${ }^{7}$ The Citigroup US Broad Investment Grade Index (known as the Saloman BIG or Citigroup BIG) is a commonly used benchmark for US fixed-income funds. It measures the value of over 3,500 US investment-grade debt instruments, including Treasuries, corporates, agency debts, government sponsored debts, mortgagebacked securities and asset-backed securities.
} 


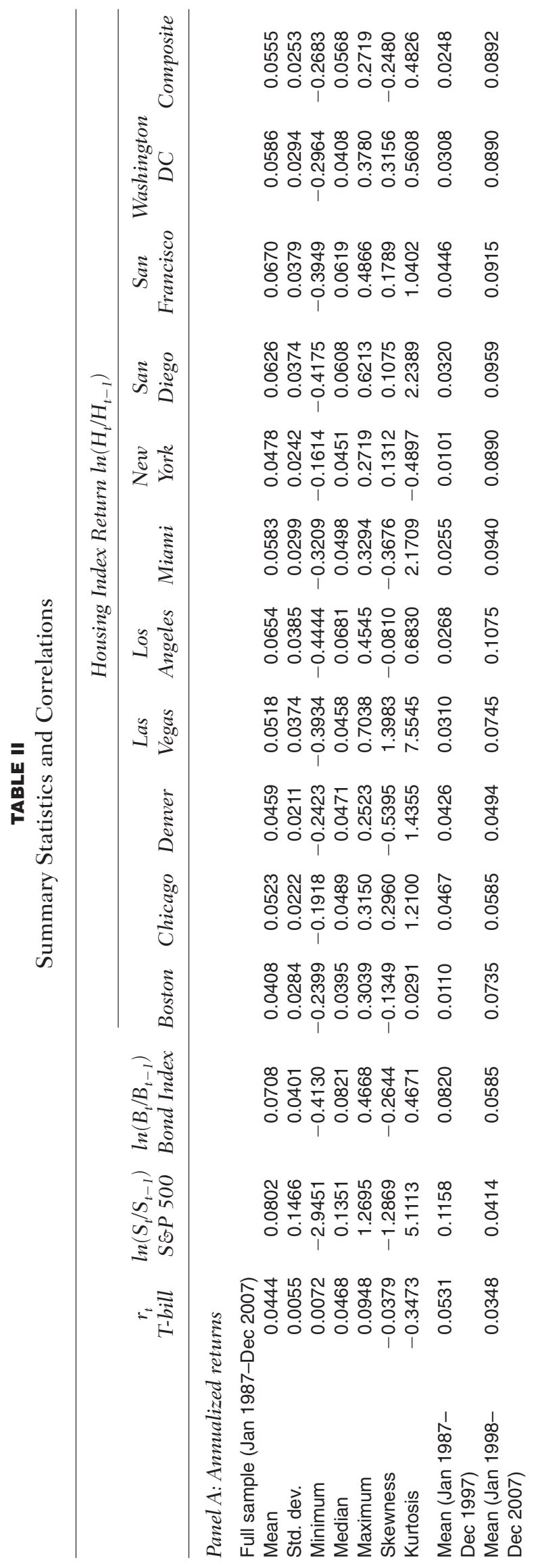




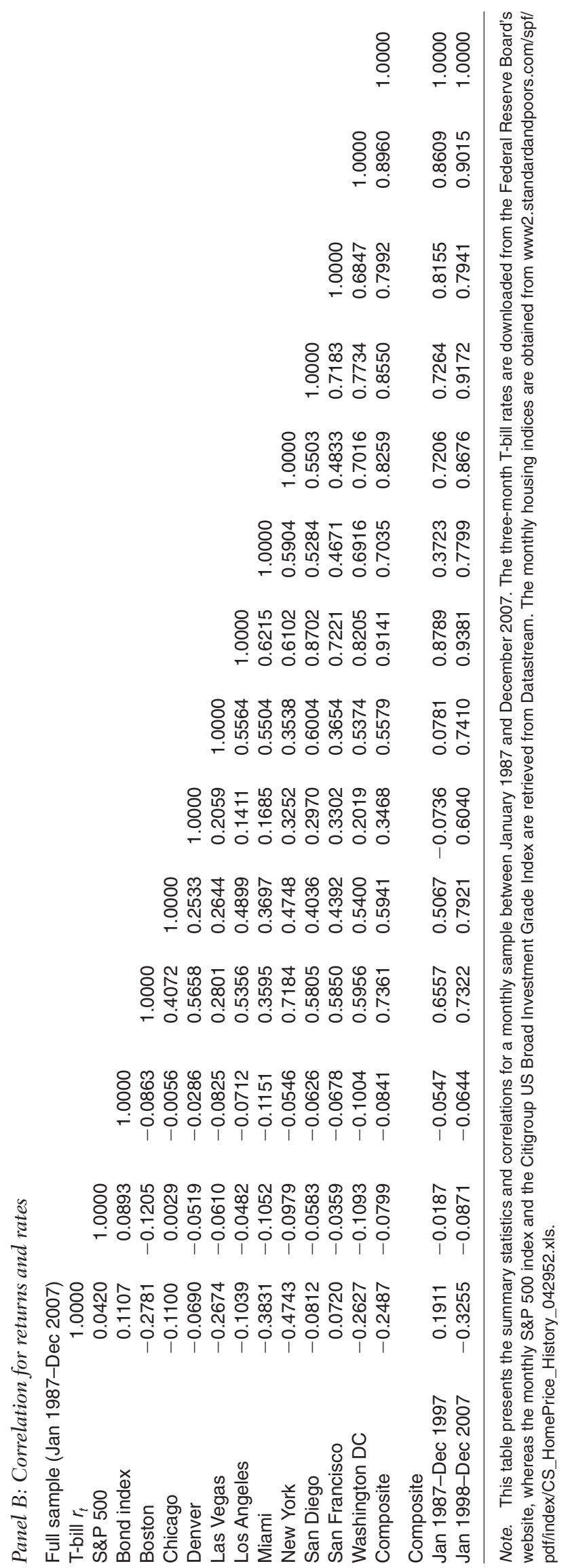


$4.08 \%$ (Boston) to $6.70 \%$ (San Francisco), slightly lower than the returns from the equity market and the bond market. However, the standard deviations for the housing indices are much smaller than those of the financial markets. Specifically, volatilities of the housing markets range from $2.22 \%$ (Chicago) to $3.85 \%$ (Los Angeles), much lower than the equity market volatility of $14.66 \%{ }^{8}$ Moreover, the skewness and kurtosis statistics suggest that the distribution of the housing market returns is close to normality, a useful fact for modeling the housing index process in third section.

The last two rows in Panel A report the average returns for the two equallength, subsample periods. Clearly, the equity and bond markets have higher average returns in the first subperiod. In contrast, the housing markets see a higher growth rate in the second subperiod.

Insofar as the magnitude of correlations is the key to diversification benefits, we report correlations in Panel B. Several observations are in order. First, the correlation between a housing index and financial market returns is generally negative. In particular, correlations with the equity index range from 0.0029 (Chicago) to -0.1205 (Boston), whereas correlations with the bond index range from -0.0056 (Chicago) to -0.1151 (Miami). Second, housing indices are also negatively correlated with the interest rate and the magnitude of correlations is generally larger compared with the correlations with the equity and bond indices. Specifically, the correlations between housing indices and the interest rates range from -0.0812 (San Diego) to -0.4743 (New York). Third, as expected, the correlations among the housing market returns themselves are positive, ranging from 0.1411 to 0.8702 . In addition, each index is highly correlated with the composite index, with Los Angeles having the highest correlation of 0.9141 , whereas Denver having the lowest of 0.3468 .

The two subperiods witnessed similar correlation behaviors. For brevity, we only report the correlations for the composite index in the last two rows of Panel B. The composite index is negatively correlated with the equity and bond indices in the two subperiods, and is highly correlated with other metropolitan housing indices. It is worth noting that the correlation between the composite index and the interest rate is positive in the first subperiod, whereas negative in the second. As shown later, different levels of correlation have different effects on risk premiums. ${ }^{9}$

\footnotetext{
${ }^{8}$ As shown in Milevsky (2004), similar housing market returns and volatilities are observed in Canada.

${ }^{9}$ The positive correlation for the period of 1987-1997 is mostly due to the macroeconomic activities in the recession years, 1991 and 1992 . Prior to the recession, the real estate value was growing as the economy heated up while the Federal Reserve was jacking up the interest rate to fend off inflation and cool down the economy, hence the positive correlation. During the recession, the interest rate was on the way down gradually, accompanied by the decline of the real estate market, again leading to a positive correlation. The second subperiod (1998-2007) saw a normally growing economy in which lower interest rates would stimulate the real estate market, hence the negative correlation.
} 
TABLE III

Efficient Portfolios With or Without Housing Index

\begin{tabular}{|c|c|c|c|c|c|c|c|}
\hline \multirow[b]{2}{*}{ Sample Period } & & \multicolumn{2}{|c|}{$\begin{array}{l}\text { Global Minimum } \\
\text { Variance Portfolio }\end{array}$} & \multicolumn{4}{|c|}{ Portfolio Risk $\sigma_{p}$} \\
\hline & & $E\left(r_{G M V}\right)$ & $\sigma_{G M V}$ & $20 \%$ & $30 \%$ & $40 \%$ & $50 \%$ \\
\hline \multirow[t]{2}{*}{ Jan 1987-Dec 2007} & Base case expected return $r_{p}$ & $7.13 \%$ & $3.94 \%$ & $8.37 \%$ & $9.02 \%$ & $9.66 \%$ & $10.30 \%$ \\
\hline & Adding the composite index & $6.04 \%$ & $2.03 \%$ & $12.53 \%$ & $15.80 \%$ & $19.07 \%$ & $22.33 \%$ \\
\hline \multirow[t]{2}{*}{ Jan 1987-Dec 1997} & Base case expected return $r_{p}$ & $8.20 \%$ & $4.43 \%$ & $12.99 \%$ & $15.48 \%$ & $17.96 \%$ & $20.42 \%$ \\
\hline & Adding the composite index & $3.47 \%$ & $1.73 \%$ & $27.15 \%$ & $39.07 \%$ & $50.98 \%$ & $62.88 \%$ \\
\hline \multirow[t]{2}{*}{ Jan 1998-Dec 2007} & Base case expected return $r_{p}$ & $5.69 \%$ & $3.17 \%$ & $7.81 \%$ & $8.89 \%$ & $9.97 \%$ & $11.04 \%$ \\
\hline & Adding the composite index & $7.50 \%$ & $1.97 \%$ & $22.16 \%$ & $29.54 \%$ & $36.91 \%$ & $44.28 \%$ \\
\hline
\end{tabular}

Note. This table presents the efficient portfolio returns based on the sample means, standard deviations and correlations presented in Table II. The sample period is between January 1987 to December 2007. The 3-month T-bill rates are retrieved from the Federal Reserve Board's website whereas the monthly S\&P 500 index and the Citigroup US Broad Investment Grade Index are retrieved from Datastream. The monthly housing indices are obtained from www2.standardandpoors.com/spf/pdf/index/CS_HomePrice_ History_042952.xls.

The overall negative correlation between housing index returns and financial market returns indicates significant diversification benefits should the housing indices be introduced to a portfolio. Table III confirms this conjecture. The first row in Table III presents the base case where the portfolio choice set includes the risk-free asset, the S\&P 500, and the bond index. The global minimum variance portfolio has an annualized expected return of $7.13 \%$ and an annualized return volatility of $3.94 \%$. A portfolio with a return volatility of $20 \%$ has an annualized expected return of $8.37 \%$. The second row in Table III presents results when the composite housing index is added to the portfolio. ${ }^{10}$ It is evident that the housing index can significantly improve the portfolio return for a given portfolio risk. For example, for a $20 \%$ portfolio volatility, the addition of the composite housing index improves the portfolio return by $4.16 \%$ (i.e., from 8.37 to $12.53 \%$ ). At a volatility level of $50 \%$, the improvement is $12.03 \%$ (i.e., from 10.30 to $22.33 \%$ ). Similar diversification benefits are also observed for the two subperiods. For example, for a $20 \%$ portfolio volatility, adding the composite index can improve the portfolio return by $14.16 \%$ in the first subperiod and $14.35 \%$ in the second. The diversification benefits are similar to those documented by Quigley (2006) for the European markets. For example, Quigley (2006) showed that, by including the Denmark housing index into the base portfolio set, the net return benefit is $12.73 \%$ for a $50 \%$ portfolio volatility.

The results in Table III clearly demonstrate the tremendous diversification benefit brought about by the housing indices. A natural question is: How come investors are not flocking to the housing derivatives market to take advantage of

\footnotetext{
${ }^{10} \mathrm{We}$ have also calculated the diversification benefit for each individual housing index. The results are similar to those of the composite housing index and are omitted for brevity.
} 
this benefit? One reason might be the lack of awareness of this benefit; another might be the lack of liquidity. Both in turn affect each other. A virtuous mutual feedback would improve both, just like the recent development in the weather derivatives market.

\section{EQUILIBRIUM VALUATION OF THE HOUSING INDEX DERIVATIVES}

\section{Structure of the Economy}

In this section, we propose an equilibrium model to accommodate the nontradability of housing indices. In particular, we extend Lucas' discrete model for a pure exchange economy with a financial market (Lucas, 1978) to a continuous-time economy with a financial market as well as a housing market. As is standard, each agent can trade a single risky stock, pure discount bonds and a finite number of other contingent claims written on the risky stock, the pure discount bond or on the house. The risky stock can be viewed as the market portfolio and its dividend stream $\left\{\delta_{t}\right\}$ can be understood as the aggregate dividend in the economy. The total supply of the market portfolio is normalized to one share, while the risk-free bond and contingent claims are all in zero net supply.

Initially, the representative agent is endowed with one share of the market portfolio and one house. The agent has a working life up to time $T$ and postretirement life span up to $\bar{T}$. The work yields a constant wage $y$ per unit of time. The agent's objective is to maximize the present value of his expected utility from the pre-retirement consumption and the post-retirement wealth. To capture the essence of a home ownership constraint, we follow Cauley, Pavlov, and Schwartz (2007) and assume that the agent cannot sell the house until his retirement at time $T .{ }^{11}$ In other words, the agent plans to consume a fixed flow of housing service until retirement.

The uncertainties in the economy are created by the aggregate dividend $\left\{\delta_{t}\right\}$ and the housing value $\left\{H_{t}\right\}$. We assume that $\delta_{t}$ and $H_{t}$ follow some exogenous Markov processes on a given probability space $(\Omega, F, P)$. Denote the financial asset prices at time $t$ by a vector $X_{t}$ and the corresponding vector of dividends by $q_{t}$. The cumulative dividends up to time $\mathrm{t}$ are defined as $D_{t} \equiv \int_{0}^{t} q_{\tau} d \tau$. The agent's information structure is given by the filtration $F_{t}\left(\delta_{\tau}, H_{\tau}, 0 \leq \tau \leq \mathrm{t}\right)$.

\footnotetext{
${ }^{11}$ As argued by Cauley et al. (2007), this housing consumption constraint captures the essence of the constraint faced by many mid-career families. That is, these families cannot afford to step up and are reluctant to step down in terms of their family houses.
} 
Denote the representative agent's portfolio holdings at time $t$ as $\theta_{t}=\left(\theta_{t}^{s}, \theta_{t}^{B}, \theta_{t}^{x^{\prime}}\right)$, where $\theta_{t}^{s}, \theta_{t}^{B}$, and $\theta_{t}^{x^{\prime}}$ indicate the number of shares held in the market portfolio, the discount bond and other contingent claims, respectively. The agent finances his consumption by his labor income and a continuous trading strategy $\left\{\theta_{t}, t \geq 0\right\}$.

Similar to Cauley et al. (2007), we assume that the pre-retirement utility function is time-separable and separable between the housing consumption and the nonhousing consumption. Furthermore, we assume that the nonhousing service is independent of the market value of the home because the utility derived by living in a house depends on its physical characteristics. Given these assumptions, we formulate the agent's optimization problem as follows:

$$
\begin{aligned}
\max _{\left\{c_{t}, \theta_{t}\right\}} E\left[\int_{0}^{T} e^{-\phi t} U\left(c_{t}\right) d t+e^{-\phi T} U\left(W_{T}\right)\right] \\
\text { s.t. } H_{t}+\theta_{t} \cdot X_{t}+\int_{0}^{t}\left(c_{\tau}-y_{\tau}\right) d \tau=\theta_{0} \cdot X_{0}+H_{0}+\int_{0}^{t} \theta_{\tau} \cdot d D_{\tau}+\int_{0}^{t} \theta_{\tau} \cdot d X_{\tau} \\
\qquad W_{T} \equiv H_{T}+\theta_{T} \cdot X_{T}
\end{aligned}
$$

where $\phi$ is the rate of time preference.

The budget constraint states that the agent's cumulative consumption up to $t$ is financed by labor income, the net selling of his securities $\left(\theta_{0} \cdot X_{0}-\theta_{t} \cdot X_{t}\right)$ plus the cumulative dividends and cumulative capital gains. The first-order conditions lead to the usual stochastic Euler equation: $X_{t}=e^{-\phi(T-t)} E\left(\int_{t}^{T} U_{c}\left(c_{\tau}\right) d D_{\tau}\right) / U_{c}\left(c_{t}\right)$. Thus, the price of any security equals the expected discounted sum of its dividends, with the marginal rate of substitution being the stochastic state price deflator.

In equilibrium, the financial market clearing conditions dictate that the representative agent holds one share of the market portfolio and nothing of the contingent claims. The goods market clears so that consumption equals dividends generated from the market portfolio. Also, the housing market clears so that the representative agent owns one house. Therefore, the equilibrium price of any security given by the Euler equation becomes ${ }^{12}$

$$
X_{t}=\frac{e^{-\phi(T-t)}}{U_{c}\left(\delta_{t}\right)} E\left(\int_{t}^{T} U_{c}\left(\delta_{\tau}\right) d D_{\tau}\right), \quad \forall t \in(0, T) .
$$

\footnotetext{
${ }^{12}$ Another way to formulate the agent's optimization with the home ownership constraint is to assume that the agent never sells the house, as in Cooper and $\mathrm{Ng}$ (2008). Their argument is that only $4 \%$ of the US households sell their homes each year during 1975 and 2007. Under this approach, we can obtain the same Euler equation (1).
} 
In the remainder of third section, we first specialize the above valuation equation with a particular preference and dividend and housing index processes; we then derive the closed-form formula for housing index derivatives; and lastly, we define and examine risk premiums.

\section{Dividend and Housing Index Processes}

To obtain closed-form solutions, we adopt a utility function with constant relative risk aversion, that is, $U\left(c_{t}\right)=c_{t}^{1-\gamma} /(1-\gamma)$, where $\gamma$ is the risk-aversion parameter. In addition, we assume a mean-reverting dividend process for the market portfolio by appealing to Marsh and Merton (1987).

Assumption 1: The aggregate dividend process is governed by the following stochastic process:

$$
d \delta_{t} / \delta_{t}=\left(\mu_{\delta}-a_{\delta} \ln \delta_{t}\right) d t+\sigma_{\delta} d z_{\delta t}
$$

where $z_{\delta t}$ is a standard Wiener process, $a_{\delta}$ is the mean-reverting speed, $\sigma_{\delta}$ is the volatility, and $\mu_{\delta}$ is the expected growth rate for the aggregate dividend.

In this economy, the other source of uncertainty is induced by the housing market fluctuations. Based on the empirical evidence presented in Table II, we model the housing index return as a geometric Brownian motion.

Assumption 2: The housing index process is governed by the following stochastic process:

$$
d H_{t} / H_{t}=\mu_{H} d t+\sigma_{H} d z_{H t}
$$

where $z_{H t}$ is a standard Wiener process, and the correlation between $d z_{\delta}$ and $d z_{H}$ is $\rho$. The expected return for the housing index is $\mu_{H}$ and its volatility is $\sigma_{H}$.

The assumed utility function allows us to determine the equilibrium price of a pure discount bond by $(1)$ as $B_{t}(T)=e^{-\phi(T-t)} E_{t}\left(\frac{U_{c}\left(\delta_{T}\right)}{U_{c}\left(\delta_{t}\right)} \times 1\right)$. Define the yield-to-maturity as $R(t, T)=-\frac{1}{T-t} \ln B_{t}(T)$, the instantaneous risk-free rate is obtained as $r_{t} \equiv \lim _{T \rightarrow t} R(t, T)$. Appendix A provides the proof for the following proposition.

Proposition 3.1: The equilibrium yield-to-maturity $R(t, T)$ and the instantaneous risk-free rate $r_{t}$ are, respectively

$$
\begin{aligned}
R(t, T) & =\phi-\frac{1}{2} \gamma^{2} \sigma_{\delta}^{2} \frac{1-e^{-2 a_{\delta}(T-t)}}{2 a_{\delta}(T-t)}+\gamma\left(\mu_{\delta}-\frac{1}{2} \sigma_{\delta}^{2}-a_{\delta} \ln \delta_{t}\right) \frac{1-e^{-a_{\delta}(T-t)}}{a_{\delta}(T-t)} \\
r_{t} & =\lim _{T \rightarrow t} R(t, T)=\phi-\frac{1}{2} \gamma^{2} \sigma_{\delta}^{2}+\gamma\left(\mu_{\delta}-\frac{1}{2} \sigma_{\delta}^{2}-a_{\delta} \ln \delta_{t}\right) .
\end{aligned}
$$


The instantaneous risk-free rate follows a mean-reverting process similar to that in Vasicek (1977) $d r_{t}=a_{\delta}\left(\phi-\frac{1}{2} \gamma^{2} \sigma_{\delta}^{2}-r_{t}\right) d t-\gamma a_{\delta} \sigma_{\delta} d z_{\delta t}$. That is, the spot risk-free rate has a mean reversion speed of $a_{\delta}$, a long-run mean of $\phi-0.5 \gamma^{2} \sigma_{\delta}^{2}$ and a volatility of $\gamma \alpha_{\delta} \sigma_{\delta}$.

The challenge of applying the equilibrium model lies in the fact that the aggregate dividend process and the risk-aversion parameter of the representative agent are not observable. Fortunately, we can bypass this difficulty by utilizing the relationship between $\delta_{t}$ and $r_{t}$ and by using the fact that $r_{t}$ is observable. Specifically, given the linear relationship between $\ln \delta_{t}$ and the endogenized interest rate $r_{t}$, we can infer the parameters for the aggregate dividend process from the observed interest rates. To do so, we re-parameterize the interest rate process as

$$
d r_{t}=a_{r}\left(b_{r}-r_{t}\right) d t+\sigma_{r} d z_{r t}
$$

That is, we can replace the parameters for the aggregate dividend process by those of the interest rate using the following relations: $a_{r}=a_{\delta}, b_{r}=\phi-\frac{1}{2}\left(\frac{\sigma_{r}}{a_{r}}\right)^{2}$, $\sigma_{r}=\gamma a_{\delta} \sigma_{\delta}, \rho_{r H}=-\rho$. Accordingly, the yield-to-maturity can be re-expressed as:

$$
R(t, T)=b_{r}+\frac{1}{2}\left(\frac{\sigma_{r}}{a_{r}}\right)^{2}\left[1-\frac{1-e^{-2 a_{r}(T-t)}}{2 a_{r}(T-t)}\right]+\left(r_{t}-b_{r}\right) \frac{1-e^{-a_{r}(T-t)}}{a_{r}(T-t)} .
$$

With the above results, we proceed to the pricing of housing index derivatives.

\section{Equilibrium Valuation of Housing Index Derivatives}

The value of a forward contract at time $t, f_{t}\left(H_{t}, K, T\right)$ with a delivery price $K$ and a maturity $T \geq t$ can be determined through the Euler equation (1) as $f_{t}\left(H_{t}, K, T\right)=e^{-\phi(T-t)} E\left(\frac{U_{c}\left(\delta_{T}\right)}{U_{c}\left(\delta_{t}\right)}\left(H_{T}-K\right)\right)$. At the initiation, the forward price at time $t, F_{t}\left(H_{t}, T\right)$, is set to be the delivery price $K$ so that the value of the forward contract is zero. Thus, we have $F_{t}\left(H_{t}, T\right)=\frac{E\left[U_{c}\left(\delta_{T}\right) H_{T}\right]}{E\left[U_{c}\left(\delta_{T}\right)\right]}$. Similarly, we can use (1) to value European call and put options with a strike price $K$ and a maturity $T \geq t$. Their prices at time $t, c_{t}\left(H_{t}, K, T\right)$ and $p_{t}\left(H_{t}, K, T\right)$, are determined as

$$
c_{t}\left(H_{t}, K, T\right)=e^{-\phi(T-t)} E_{t}\left(\frac{U_{c}\left(\delta_{T}\right)}{U_{c}\left(\delta_{t}\right)} \max \left(H_{T}-K, 0\right)\right)
$$

and

$$
p_{t}\left(H_{t}, K, T\right)=e^{-\phi(T-t)} E_{t}\left(\frac{U_{c}\left(\delta_{T}\right)}{U_{c}\left(\delta_{t}\right)} \max \left(K-H_{T}, 0\right)\right) .
$$


To facilitate the presentation of option prices, let $C_{B S}$ and $P_{B S}$ stand for the Black-Scholes (Black \& Scholes, 1973) call and put values with the following expression:

$$
\begin{aligned}
& C_{B S}\left(S_{t}, \tau, K ; r, q, \sigma\right)=S_{t} e^{-q \tau} N\left(d_{1}\right)-K e^{-r \tau} N\left(d_{2}\right) \\
& P_{B S}\left(S_{t}, \tau, K ; r, q, \sigma\right)=K e^{-r \tau} N\left(-d_{2}\right)-S_{t} e^{-q \tau} N\left(-d_{1}\right)
\end{aligned}
$$

with

$$
d_{1}=\frac{\ln \left(S_{t} / K\right)+\left(r-q+\sigma^{2} / 2\right) \tau}{\sigma \sqrt{\tau}} \quad \text { and } \quad d_{2}=d_{1}-\sigma \sqrt{\tau} .
$$

The following proposition states the forward price, the value of a forward contract and European call and put prices. Proofs are summarized in Appendix B.

Proposition 3.2: The equilibrium housing forward price at time $t$ with a maturity $T \geq t, F_{t}\left(H_{t}, T\right)$, and the value of a forward contract at time $t$ with a delivery price $K$ and a maturity $T \geq t, f_{t}\left(H_{t}, K, T\right)$, are

$$
F_{t}\left(H_{t}, T\right)=H_{t} \exp \left(\mu_{H}(T-t)+\rho_{r H} \sigma_{H} \frac{\sigma_{r}}{a_{r}^{2}}\left(1-e^{-a_{r}(T-t)}\right)\right)
$$

and

$$
f_{t}\left(H_{t}, K, T\right)=\left[F_{t}\left(H_{t}, T\right)-K\right] e^{-R(t, T)(T-t)} .
$$

The equilibrium prices of European call and put options at time $t$ with a strike price $K$ and a maturity $T \geq t$ are

$$
c_{t}\left(H_{t}, K, T\right)=C_{B S}\left(F_{t}\left(H_{t}, T\right), T-t, K ; R(t, T), R(t, T), \sigma_{H}\right)
$$

and

$$
p_{t}\left(H_{t}, K, T\right)=P_{B S}\left(F_{t}\left(H_{t}, T\right), T-t, K ; R(t, T), R(t, T) \sigma_{H}\right) .
$$

The forward price increases with the expected growth rate of the housing market $\mu_{H}$, its volatility $\sigma_{H}$, the volatility of the interest rate $\sigma_{r}$, and the correlation between the housing index and the interest rate $\rho_{r H}$; it decreases with the mean revision speed for the interest rate $a_{r}$. The long-run mean of the interest rate has no effect on the forward price. Proposition 3.2 also indicates that the value of a forward or option contract is priced in the traditional way, once the forward price is determined.

\section{Risk Premiums for Housing Index Derivatives}

The nontradability of housing indices commands a risk premium in that the equilibrium value of a derivative is generally different from a preference-free value 
of the same derivative. To gauge this risk premium, we need to derive the riskneutral values of forwards and options contracts. To this end, we require the risk-neutral processes corresponding to (3) and (4). Let's start with the risk-free interest rate. The equilibrium price of a pure discount bond is $d B_{t} / B_{t}=\left[r_{t}+\right.$ $\left.\gamma^{2} \sigma_{\delta}^{2}\left(1-e^{-a_{\delta}(T-t)}\right)\right] d t+\gamma \sigma_{\delta}\left(1-e^{-a_{\delta}(T-t)}\right) d z_{\delta t}$. We can then write the risk-neutral process as $d B_{t} / B_{t}=r_{t} d t+\gamma \sigma_{\delta}\left(1-e^{-a_{\delta}(T-t)}\right) d z_{\delta t}$, where $d z_{\delta}^{Q}=\gamma \sigma_{\delta} d t+d z_{\delta}$, which in turn implies the following the risk-neutral process for the risk-free rate under the re-parameterization

$$
d r_{t}=a_{r}^{Q}\left(b_{r}^{Q}-r_{t}\right) d t+\sigma_{r}^{Q} d z_{r t}^{Q}=a_{r}\left[b_{r}+\left(\frac{\sigma_{r}}{a_{r}}\right)^{2}-r_{t}\right] d t+\sigma_{r} d z_{r t}^{Q} .
$$

The expressions in (4) and (8) indicate that the only difference between the risk-neutral and the equilibrium processes lies in the long-run mean, with the risk-neutral long-run mean being higher by $\left(\sigma_{r} / a_{r}\right)^{2}$. Accordingly, the yield-tomaturity in the risk-neutral world can be written as

$$
\begin{aligned}
R^{Q}(t, T) & =-\frac{1}{T-t} \ln E_{t}\left[e^{-\int_{t}^{T} r_{s} d s}\right] \\
& =b_{r}^{Q}-\frac{1}{2}\left(\frac{\sigma_{r}}{a_{r}}\right)^{2}-\frac{\sigma_{r}^{2}}{4 a_{r}^{3}} \frac{1-e^{-2 a_{r}(T-t)}}{(T-t)}+\left(r_{t}-b_{r}^{Q}+\frac{\sigma_{r}^{2}}{a_{r}^{2}}\right) \frac{1-e^{-a_{r}(T-t)}}{a_{r}(T-t)} .
\end{aligned}
$$

As $b_{r}^{Q}=b_{r}+\frac{\sigma_{r}^{2}}{a_{r}^{2}}$, it is easy to show that the yield-to-maturity in the riskneutral world, $R^{Q}(t, T)$, is the same as the equilibrium yield-to-maturity $R(t, T)$ in $(5)$.

Next, we determine the risk-neutral process for the housing index. As the risk premium is defined with respect to the situation where the housing index was taken as a traded asset, we can write down the following risk-neutral process:

$$
d H_{t}^{Q} / H_{t}^{Q}=r_{t} d t+\sigma_{H} d z_{\bar{H} t}^{Q} .
$$

The interest rate and housing index processes in (8) and (9) allow us to derive the risk-neutral counterparts of the elements in Proposition 3.2, summarized in the following proposition. Proofs are collected in Appendix C.

Proposition 3.3: At time $t$, the risk-neutral forward price with a maturity $T$, $F_{t}^{Q}\left(H_{t}, T\right)$, and the value of the forward contract with a delivery price $K$ and a maturity $T, f_{t}^{Q}\left(H_{t}, K, T\right)$, are

$$
\begin{aligned}
F_{t}\left(H_{t}, T\right) & =H_{t} e^{R(t, T)(T-t)}, \\
f_{t}^{\mathcal{Q}}\left(H_{t}, K, T\right) & =\left[F_{t}^{Q}\left(H_{t}, T\right)-K\right] e^{-R(t, T)(T-t)}, \quad \forall \quad T \geq t .
\end{aligned}
$$


The risk-neutral European call and put prices with a strike price $K$ and a maturity $T \geq t$ are

$$
\begin{aligned}
c_{t}^{Q}\left(H_{t}, K, T\right) & =C_{B S}\left(H_{t}, T-t, K ; R(t, T), 0, \hat{\sigma}_{H}\right), \\
p_{t}^{Q}\left(H_{t}, K, T\right) & =P_{B S}\left(H_{t}, T-t, K ; R(t, T), 0, \hat{\sigma}_{H}\right),
\end{aligned}
$$

with

$$
\begin{aligned}
& \hat{\sigma}_{H}= \\
& \sqrt{\sigma_{H}^{2}+2 \rho_{r H} \sigma_{H} \frac{\sigma_{r}}{a_{r}}\left(1-\frac{1-e^{-a_{r}(T-t)}}{a_{r}(T-t)}\right)+\frac{\sigma_{r}^{2}}{a_{r}^{2}}\left(1-2 \frac{1-e^{-a_{r}(T-t)}}{a_{r}(T-t)}+\frac{1-e^{-2 a_{r}(T-t)}}{2 a_{r}(T-t)}\right)} .
\end{aligned}
$$

Using the equilibrium and risk-neutral valuations in Propositions 3.2 and 3.3 , we define the risk premium in the forward price as

$$
\begin{aligned}
\lambda_{\text {fwd }} & =\frac{F_{t}\left(H_{t}, T\right)}{F_{t}^{Q}\left(H_{t}, T\right)}-1 \\
& =\exp \left[\left(\mu_{H}+\rho_{r H} \sigma_{H} \frac{\sigma_{r}\left(1-e^{-a_{r}(T-t)}\right)}{a_{r}^{2}(T-t)}-R(t, T)\right)(T-t)\right]-1 .
\end{aligned}
$$

Straightforward comparative static analyses show that the risk premium $\lambda_{\text {fwd }}$ increases with the expected housing index return $\mu_{H}$, its volatility $\sigma_{H}$, the correlation between the housing index and the interest rate $\rho_{r H}$, and the time to maturity of the forward contract. It decreases with the long-run mean of the interest rate $b_{r}$. Effects of the mean-reverting speed of the interest rate $a_{r}$ and the volatility of the interest rate $\sigma_{r}$ are indeterminate.

The risk premiums for call and put options can be defined in a similar fashion:

$$
\lambda_{\text {call }}=\frac{c_{t}\left(H_{t}, K, T\right)}{c_{t}^{Q}\left(H_{t}, K, T\right)}-1, \quad \text { and } \quad \lambda_{p u t}=\frac{p_{t}\left(H_{t}, K, T\right)}{p_{t}^{Q}\left(H_{t}, K, T\right)}-1
$$

The comparative statics suggests that the risk premium for a call increases with the expected housing index return $\mu_{H}$ and the correlation between the housing index and the interest rate $\rho_{r H}$. The risk premium for a put decreases with the expected housing index return $\mu_{H}$ and the correlation between the housing index and the interest rate $\rho_{r H}$. The effects of other model parameters are indeterminate.

To assess the magnitude of the actual risk premiums embedded in the CME contracts, we perform numerical analyses in the next section. 
TABLE IV

Model Parameters Estimated With the Maximum-Likelihood Method

\begin{tabular}{|c|c|c|c|c|c|c|c|}
\hline \multirow[b]{2}{*}{ Sample Period } & \multicolumn{2}{|c|}{$\begin{array}{c}\text { Composite } \\
\text { Housing } \\
\text { Index } H_{t} \\
\end{array}$} & \multicolumn{3}{|c|}{ T-bill $r_{t}$} & \multirow{2}{*}{$\begin{array}{c}\text { Correlation } \\
\rho_{r H}\end{array}$} & \multirow[b]{2}{*}{ Log-Likelihood } \\
\hline & $\mu_{H}(\%)$ & $\sigma_{H}(\%)$ & $a_{r}$ & $b_{r}$ & $\sigma_{r}$ & & \\
\hline Jan 1987-Dec 2007 & $\begin{array}{c}5.587 \\
(0.544)\end{array}$ & $\begin{array}{c}2.524 \\
(0.113)\end{array}$ & $\begin{array}{c}0.468 \\
(0.249)\end{array}$ & $\begin{array}{c}0.042 \\
(0.010)\end{array}$ & $\begin{array}{c}0.002 \\
(0.000)\end{array}$ & $\begin{array}{c}0.084 \\
(0.066)\end{array}$ & -2442 \\
\hline Jan 1987-Dec 1997 & $\begin{array}{c}2.493 \\
(0.566)\end{array}$ & $\begin{array}{c}1.924 \\
(0.119)\end{array}$ & $\begin{array}{c}1.194 \\
(0.465)\end{array}$ & $\begin{array}{c}0.054 \\
(0.006)\end{array}$ & $\begin{array}{c}0.002 \\
(0.000)\end{array}$ & $\begin{array}{c}0.177 \\
(0.085)\end{array}$ & -1293 \\
\hline Jan 1998-Dec 2007 & $\begin{array}{c}8.982 \\
(0.890)\end{array}$ & $\begin{array}{c}2.747 \\
(0.178)\end{array}$ & $\begin{array}{c}0.340 \\
(0.318)\end{array}$ & $\begin{array}{c}0.028 \\
(0.016)\end{array}$ & $\begin{array}{c}0.001 \\
(0.000)\end{array}$ & $\begin{array}{c}0.117 \\
(0.097)\end{array}$ & -1177 \\
\hline
\end{tabular}

Note. This table presents the estimated parameters for the composite housing index $\left(H_{t}\right)$ and the interest rate $\left(r_{t}\right)$ processes that are specified as $d H_{t}=\mu_{H} H d t+\sigma_{H} H_{t} d z_{H t}$ and $d r_{t}=a_{r}\left(b_{r}-r_{t}\right) d_{t}+\sigma_{r} d z_{r t}$, where $\mu_{H}$ and $\sigma_{H}$ are the expected return and volatility for the housing index, $a_{r}, b_{r}$, and $\sigma_{r}$ are the mean-reversion speed, long-run mean, and volatility for the interest rate. The correlation between $d z_{H}$ and $d z_{r}$ is $\rho_{r H}$. The monthly composite housing index is retrieved from www2.standardpoors.com/spf/pdf/index/CS_HomePrice_ History_042952.xls, whereas the three-month T-bill rates are downloaded from the Federal Reserve Board's website. All parameters are estimated using the Maximum-Likelihood Method. The numbers in parentheses are standard errors.

\section{QUANTIFYING RISK PREMIUMS FOR THE CME HOUSING INDEX DERIVATIVES}

We start by jointly estimating the model parameters for housing indices and the interest rate, using the maximum likelihood method. As results for individual housing indices are similar to those of the composite housing index, to save space, we only report estimated model parameters for the composite housing index and the interest rate in Table IV. The estimation is carried out for the full sample as well as the two subsamples. There are a few important observations.

First, the estimation of the parameters describing the composite housing index $\left(\mu_{H}\right.$ and $\left.\sigma_{H}\right)$ is quite accurate, as indicated by the small standard errors. The estimation accuracy is also reflected in the closeness between the estimates here and the corresponding statistics shown in Table II.

Second, the estimated parameters for the interest rate process exhibit similar features documented by the existing literature (e.g., Chan, Karolyi, Longstaff, \& Sanders, 1992). In particular, the estimated long-run mean is close to the corresponding sample average. Moreover, the estimation errors for the long-run mean and the volatility are small for all sample periods. In contrast, the estimation error for the reversion speed is relative large. Notwithstanding the large estimation error, the estimate for the reversion speed indicates a much faster reversion in the first subperiod.

Third, the estimated correlation between the composite housing index and the interest rate is positive, albeit with a large standard error. 


\section{Risk Premiums for CME Futures and Options on Futures}

To facilitate calculations, we take the housing index levels and the interest rate level in December 2007 as the spot values. All other parameters take on the estimated values shown in Table IV. We start with the futures contracts first.

Using equations (6) and (10), we compute futures prices and risk premiums for three different maturities: one year, two years and five years. The results are presented in Panel A of Table V. Three observations are in order. First, risk premiums increase with maturity, which confirms our comparative statics analysis. Second, the higher the expected growth rate for the underlying housing index, the higher the risk premium, again confirming the comparative static results. Third, risk premiums for futures contracts can be positive or negative, depending on the relative magnitudes of the index growth rate and the risk-free yield-to-maturity. For instance, the two-year yields-to-maturity are $3.433 \%, 4.468 \%$, and $2.987 \%$ for the full, first-half and the second-half sample periods, compared against the corresponding growth rates of $5.587 \%, 2.493 \%$, and $8.982 \%$. They result in risk premiums of $8.25 \%,-1.92 \%$, and $17.47 \%$. When the growth rate is higher than the yield-to-maturity, the risk premium is positive, and vice versa. ${ }^{13}$

We now turn to risk premiums for options. As the results are similar for calls and puts, we only discuss call options for brevity. Call prices and risk premiums for the composite index are computed based on (7) and (11) for three maturities (i.e., one year, two years, and five years) and three moneyness levels (i.e., $K / H_{t}=0.95,1$, and 1.05). Results for different maturities are qualitatively the same. So we only report the results for the two-year maturity case in Panel B of Table V. We make several important observations. First, risk premiums for call options are much higher than those for futures contracts with the same maturity.

Second, the absolute value of the risk premium for a call option decreases with its moneyness. That is, the risk premium for an in-the-money call is smaller than that for an at-the-money call, which, in turn, is smaller than that for an out-of-the-money call. For example, based on the full sample estimates, the risk premiums are $102.17 \%, 222.41 \%$, and $773.86 \%$ for the in-, at-, and out-of-themoney calls, respectively.

Third, similar to futures contracts, the higher the expected growth rate for the underlying housing index, the higher the risk premium, confirming the comparative static result. For instance, the growth rate of $8.982 \%$ for the second

\footnotetext{
${ }^{13}$ Given the current declining real estate market, the CME market quotes suggest that traders are using negative growth rates for the underlying indices, implying negative risk premiums for the CME futures contract. For example, at housingrdc.cme.com, the bid and ask for the composite index on June 30, 2008 were quoted at 171 and 177 for a November 2008 maturity, 160 and 174 for a February 2009 maturity.
} 


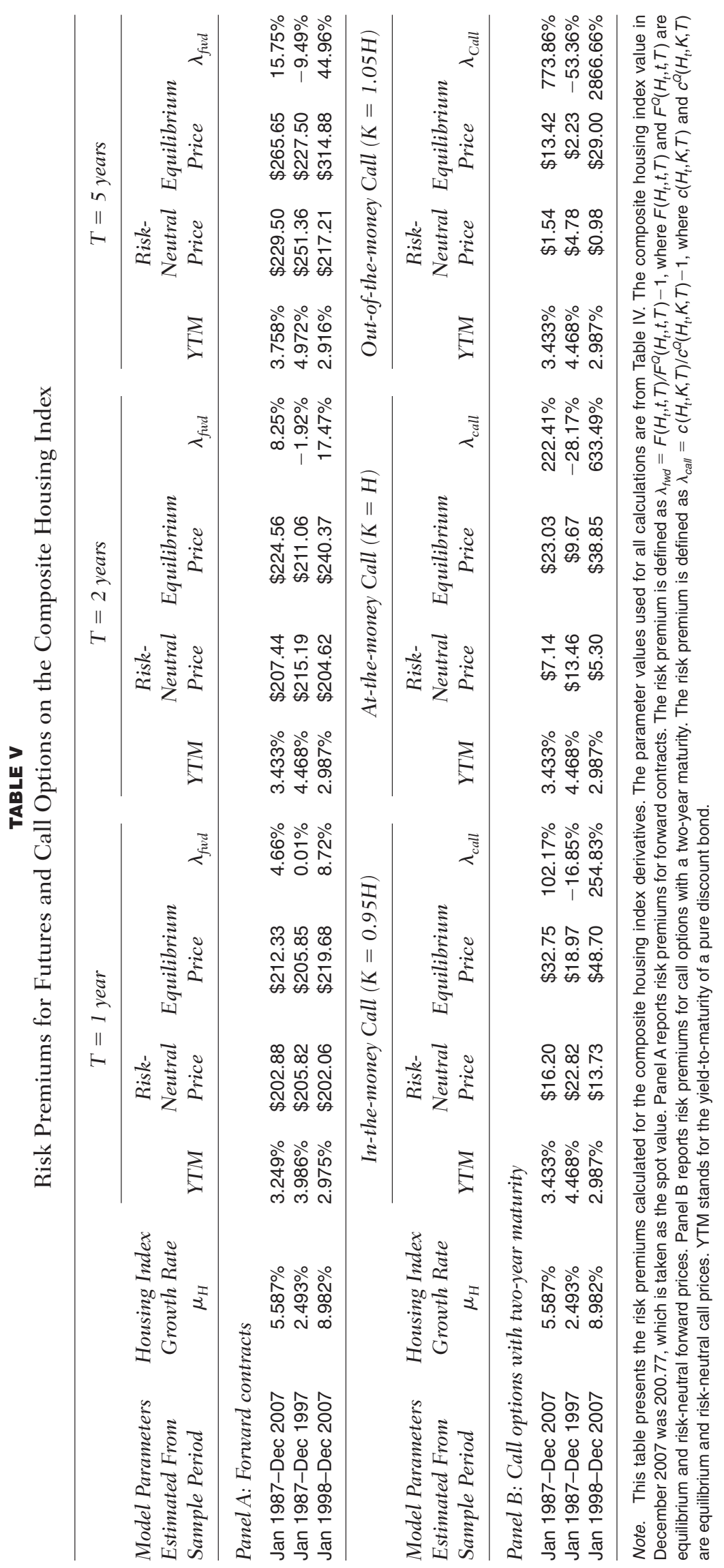


subperiod is the highest, and the second subperiod sees the largest risk premium for all moneyness levels.

Fourth, the risk premium for a call option can be either positive or negative, depending on whether the index growth rate is higher or lower than the risk-free yield-to-maturity. For instance, the risk premium is negative for all moneyness levels in the first subperiod as the growth rate is lower than the yield-to-maturity in this period.

In summary, the numerical results in Table V suggest that (1) risk premiums for futures and options are sizable for maturities longer than one year, (2) risk premiums increase with the growth rate of the underlying housing index, and (3) risk premiums can be positive or negative, depending on the relative magnitudes of the growth rate and the risk-free yield-to-maturity.

\section{Risk Premiums Versus Estimation Errors}

So far, our numerical analyses are based on estimated parameters presented in Table IV. As noted earlier, estimation errors for the interest rate mean-reversion speed $\left(a_{r}\right)$ and the correlation between the composite housing index and the interest rate $\left(\rho_{r H}\right)$ are relative large. In this subsection, we examine the marginal impacts, as well as the joint impacts, of these two estimation errors on risk premiums. Specifically, to investigate the marginal impact of the estimation error for $a_{r}$, we consider two scenarios: The value of $a_{r}$ is either below or above the estimated value by one standard error. Similar analysis is carried out for the correlation parameter $\rho_{r H}$. As for the joint effects, we consider four scenarios, all characterized by a one-standard-error distance from the estimate: (1) $a_{r}$ and $\rho_{r H}$ are both below the estimates, (2) $a_{r}$ is below, whereas $\rho_{r H}$ is above the estimates, (3) $a_{r}$ is above, whereas $\rho_{r H}$ is below the estimates, and (4) $a_{r}$ and $\rho_{r H}$ are both above the estimates. To conserve space, we only present in Table VI results for futures contracts and in-the-money calls with a twoyear maturity.

By and large, the effects of estimation errors on housing index derivative values are small. Let's first examine the marginal impact of the estimation error in the reversion speed, $a_{r}$. Panel A shows that the biggest price difference for futures is $\$ 0.06(=\$ 240.43-\$ 240.37)$ associated with the second subsample estimation. This is equivalent to a $0.025 \%$ pricing difference, which is negligible. The impact for call options is slightly bigger, but still negligible. Panel B indicates that the biggest price difference for call options is $\$ 0.57(=\$ 39.42-$ $\$ 38.85)$, translating to a $1.47 \%$ pricing difference.

The marginal effects of the estimation errors in the correlation parameter $\rho_{r H}$ are even smaller. The biggest price difference for futures is $\$ 0.01$ $(=\$ 224.57-\$ 224.56$ or $\$ 211.07-\$ 211.06)$ associated with the full sample 


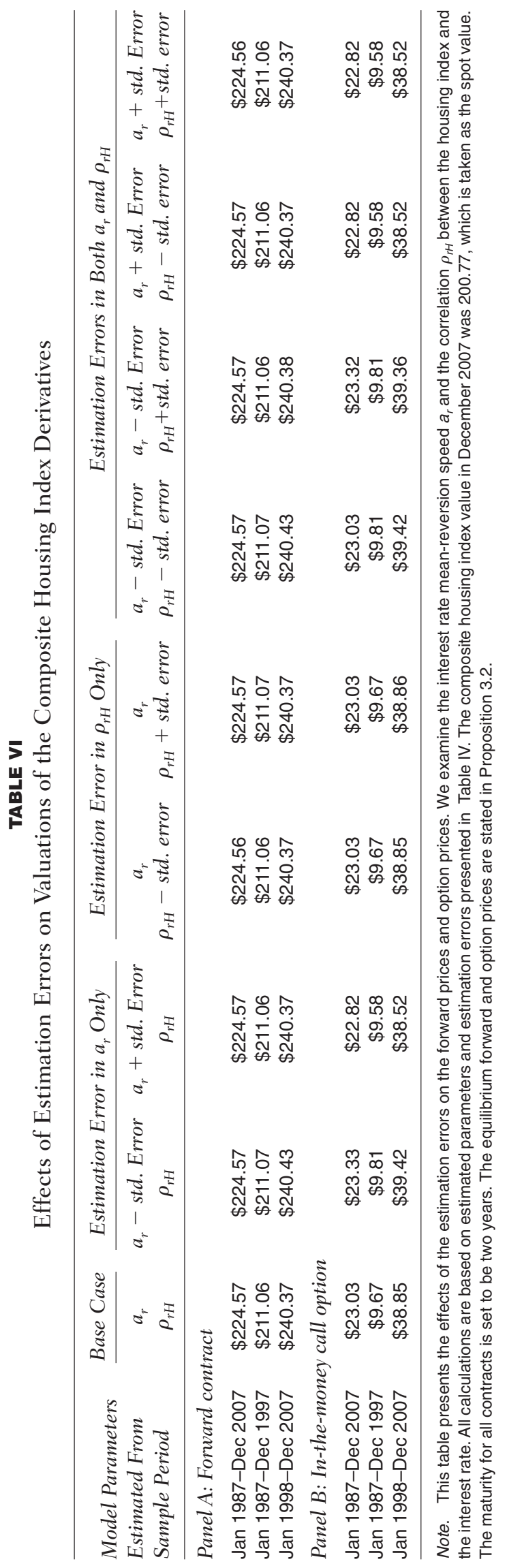


and the first subsample estimates, equivalent to a $0.0047 \%$ percentage difference. Similar results hold for calls.

The joint impacts are generally small too. The biggest price difference for futures is $\$ 0.06(=\$ 240.43-\$ 240.37)$, equivalent to a $0.025 \%$ percentage difference, whereas the biggest price difference for calls is $\$ 0.57(=\$ 39.42-$ $\$ 38.85)$, corresponding to a $1.47 \%$ percentage difference.

It seems that most of the large price differences reside in the second subperiod. One possible reason may be the higher interest rate volatility in this period. Presumably, the higher volatility amplifies the impact of estimation errors. Nevertheless, our sensitivity analyses suggest that the estimation errors in the correlation and the reversion speed parameter do not have a material impact on the values of housing index derivatives.

\section{CONCLUSION}

The lack of active trading of housing index derivatives, despite the higher price volatility of the real estate market, might be due to the absence of comprehensive valuation models. This study provides some guidance for theoretical valuation, aiming at stimulating more interests in housing index derivatives.

We first derive closed-form valuation formulas for housing index derivatives. Specifically, we implement an equilibrium valuation framework to circumvent the nontradability of housing indices. In particular, we extend Lucas' model (Lucas, 1978) and introduce housing market uncertainty to the economy as the additional source of risk. In addition to the traditional portfolio wealth, we include labor income and house value as part of the agent's overall wealth. Under the assumptions of a mean-reverting aggregate dividend process, a geometric Brownian motion for the housing index, and a preference function with constant relative risk aversion, we are able to endogenize the risk-free interest rate and obtain closed-form valuation formulas for futures and options. The formulas are comprised of parameters characterizing the underlying housing index and the interest rate, and their correlation.

We then examine the risk premiums arising from the nontradability of housing indices. To this end, we define risk premium as the percentage difference between the equilibrium value derived in our framework and the risk-neutral value derived by assuming tradability of housing indices. Aside from providing analytical, comparative statics concerning risk premiums, we also carry out numerical analyses tailored to the CME contracts. The calculation of risk premiums is facilitated by empirically estimated parameters governing the housing index process and the risk-free interest rate. Three important findings emerge. First, risk premiums are significant for all contracts with maturities longer than one year. Second, the expected growth rate of the underlying housing index is 
the key determinant for the magnitude of risk premiums. Third, risk premiums can be positive or negative, depending on whether the expected growth rate of the underlying index is higher or lower than the risk-free yield-to-maturity.

\section{APPENDIX A}

\section{Proofs of Proposition 3.1: Yield-to-Maturity and} Instantaneous Risk-Free Rate

Proof: We first derive the pure discount price with maturity $\mathrm{T}$ at time $t \leq T$. From the Euler equation (1), we have

$$
B_{t}(T)=e^{-\phi(T-t)} E_{t}\left(\frac{U_{c}\left(\delta_{T}\right)}{U_{c}\left(\delta_{t}\right)} \times 1\right)=e^{-\phi(T-t)} E_{t}\left(\left(\frac{\delta_{T}}{\delta_{t}}\right)^{-\gamma}\right), \forall t \in(0, T) .
$$

The conditional density for $\ln \delta_{T} / \ln \delta_{t}$ has a Gaussian distribution

$$
g\left(\ln \delta_{T} / \delta_{t}\right)=\frac{1}{\sqrt{2 \pi \sum_{\delta}^{2}(t, T)}} \exp \left(-\frac{1}{2} \frac{\left(\ln \delta_{T} / \delta_{t}-\Psi_{\delta}(t, T)\right)^{2}}{\sum_{\delta}^{2}(t, T)}\right)
$$

with

$$
\begin{aligned}
& \Psi_{\delta}(t, T)=\left(\mu_{\delta}-\frac{1}{2} \sigma_{\delta}^{2}-a_{\delta} \ln \delta_{t}\right) \frac{1-e^{-a_{\delta}(T-t)}}{a_{\delta}} \text { and } \\
& \Sigma_{\delta}^{2}(t, T)=\sigma_{\delta}^{2} \frac{1-e^{-2 a_{\delta}(T-t)}}{2 a_{\delta}} .
\end{aligned}
$$

Therefore, the price of a pure discount bond can be computed as follows:

$$
\begin{aligned}
B_{t}(T) & =e^{-\phi(T-t)} E_{t}\left(\left(\frac{\delta_{T}}{\delta_{t}}\right)^{-\gamma}\right)=e^{-\phi(T-t)} e^{-\gamma \Psi_{\delta}(t, T)+\frac{1}{2} \gamma^{2} \Sigma_{\delta}^{2}(t, T)} \\
& =\exp \left[-\phi+\frac{1}{2} \gamma^{2} \sigma_{\delta}^{2} \frac{1-e^{-2 a_{\delta}(T-t)}}{2 a_{\delta}(T-t)}-\gamma\left(\mu_{\delta}-\frac{1}{2} \sigma_{\delta}^{2}-a_{\delta} \ln \delta_{t}\right) \frac{1-e^{-a_{\delta}(T-t)}}{a_{\delta}(T-t)}\right] .
\end{aligned}
$$

The yield-to-maturity, $R(t, T)$, is defined through $e^{-R(t, T)(T-t)} \equiv B_{t}(T)$. Therefore,

$$
R(t, T)=\phi-\frac{1}{2} \gamma^{2} \sigma_{\delta}^{2} \frac{1-e^{-2 a_{\delta}(T-t)}}{2 a_{\delta}(T-t)}+\gamma\left(\mu_{\delta}-\frac{1}{2} \sigma_{\delta}^{2}-a_{\delta} \ln \delta_{t}\right) \frac{1-e^{-a_{\delta}(T-t)}}{a_{\delta}(T-t)} .
$$

Then, the spot instantaneous interest rate $r_{t}$ is

$$
r_{t}=\lim _{T \rightarrow t} R(t, T)=\phi-\frac{1}{2} \gamma^{2} \sigma_{\delta}^{2}+\gamma\left(\mu_{\delta}-\frac{1}{2} \sigma_{\delta}^{2}-a_{\delta} \ln \delta_{t}\right) .
$$




\section{APPENDIX B}

\section{Proof of Proposition 3.2: Equilibrium Valuation of Housing Index Derivatives}

Proof: The value of a forward contract with a maturity $T$ and a delivery price $K$ is determined as

$$
\begin{aligned}
f_{t}\left(H_{t}, K, T\right) & =e^{-\phi(T-t)} E_{t}\left(\frac{U_{c}\left(\delta_{T}\right)}{U_{c}\left(\delta_{t}\right)}\left(H_{T}-K\right)\right) \\
& =e^{-\phi(T-t)} E_{t}\left(\left(\frac{\delta_{T}}{\delta_{t}}\right)^{-\gamma} H_{T}\right)-K e^{-R(t, T)(T-t)} .
\end{aligned}
$$

The conditional joint density for $\left(\ln \delta_{T} / \delta_{t}, \ln H_{T} / H_{t}\right)$ is

$$
\begin{aligned}
& g\left(\ln \delta_{T} / \delta_{t}, \ln H_{T} / H_{t}\right)=\frac{1}{2 \pi \Sigma_{\delta}(t, T) \Sigma_{H}(t, T) \sqrt{1-\hat{\rho}^{2}}} \\
& \quad \times \exp \left\{\frac { - 1 } { 2 ( 1 - \hat { \rho } ^ { 2 } ) } \left[\left(\frac{\ln \delta_{T} / \delta_{t}-\Psi_{\delta}(t, T)}{\Sigma_{\delta}(t, T)}\right)^{2}\right.\right. \\
& \left.\left.\quad-2 \hat{\rho} \frac{\ln \delta_{T} / \delta_{t}-\Psi_{\delta}(t, T)}{\Sigma_{\delta}(t, T)} \frac{\ln H_{T} / H_{t}-\Psi_{H}(t, T)}{\Sigma_{H}(t, T)}+\left(\frac{\ln H_{T} / H_{t}-\Psi_{H}(t, T)}{\Sigma_{H}(t, T)}\right)^{2}\right]\right\}
\end{aligned}
$$

with $\Psi_{\delta}(t, T)$ and $\Sigma_{\delta}(t, T)$ being defined in (A1), and

$$
\begin{aligned}
& \Psi_{H}(t, T)=\left(\mu_{H}-\frac{1}{2} \sigma_{H}^{2}\right)(T-t), \Sigma_{H}^{2}(t, T)=\sigma_{H}^{2}(T-t), \\
& \operatorname{cov}\left(\ln \delta_{T} / \delta_{t}, \ln H_{T} / H_{t}\right)=\rho \sigma_{H} \sigma_{\delta} \frac{1-e^{-a_{\delta}(T-t)}}{a_{\delta}(T-t)}, \text { and } \\
& \hat{\rho}=\frac{\operatorname{cov}\left(\ln \delta_{T} / \delta_{t}, \ln H_{T} / H_{t}\right)}{\Sigma_{\delta}(t, T) \Sigma_{H}(t, T)} .
\end{aligned}
$$

Therefore, the value of a forward contract is computed as

$$
\begin{aligned}
f_{t}\left(H_{t}, K, T\right)= & e^{-\phi(T-t)} E_{t}\left(\left(\frac{\delta_{T}}{\delta_{t}}\right)^{-\gamma} H_{T}\right)-K e^{-R(t, T)(T-t)} \\
= & H_{t} e^{-\phi(T-t)} e^{-\gamma \Psi_{\delta}(t, T)+\frac{1}{2} \gamma^{2} \Sigma_{\delta}^{2}(t, T)} e^{\Psi_{H}(t, T)+\frac{1}{2} \Sigma_{H}^{2}(t, T)-\gamma \operatorname{cov}\left(\ln \delta_{T} / \delta_{t} \ln H_{T} / H_{t}\right)} \\
& -K e^{-R(t, T)(T-t)} \\
= & H_{t} \exp \left(\mu_{H}(T-t)-\rho \gamma \sigma_{H} \frac{\sigma_{\delta}}{a_{\delta}}\left(1-e^{-a_{\delta}(T-t)}\right)\right) e^{-R(t, T)(T-t)} \\
& -K e^{-R(t, T)(T-t)} .
\end{aligned}
$$


At the initiation, we set the value of the forward contract to be zero to obtain the forward price. That is, the forward price is

$$
F_{t}\left(H_{t}, T\right)=K=H_{t} \exp \left(\mu_{H}(T-t)-\rho \gamma \sigma_{H} \frac{\sigma_{\delta}}{a_{\delta}}\left(1-e^{-a_{\delta}(T-t)}\right)\right) .
$$

Given the re-parameterization

$$
a_{\delta}=a_{r}, \phi=b_{r}+\frac{1}{2}\left(\frac{\sigma_{r}}{a_{r}}\right)^{2}, \gamma a_{\delta} \sigma_{\delta}=\sigma_{r}, \rho=-\rho_{r H}
$$

we have

$$
F_{t}\left(H_{t}, T\right)=H_{t} \exp \left(\mu_{H}(T-t)+\rho_{r H} \sigma_{H} \frac{\sigma_{r}}{a_{r}^{2}}\left(1-e^{-a_{r}(T-t)}\right)\right) .
$$

Thus, we can restate the value of the forward contract as

$$
f_{t}\left(H_{t}, K, T\right)=\left[F_{t}\left(H_{t}, T\right)-K\right] e^{-R(t, T)(T-t)} .
$$

Now we consider a European call option with a maturity $T$ and a strike price $K$ on the housing index. It is priced as follows:

$$
c_{t}\left(H_{t}, K, T\right)=e^{-\phi(T-t)} E_{t}\left(\left(\frac{\delta_{T}}{\delta_{t}}\right)^{-\gamma} \max \left(H_{T}-K, 0\right)\right) .
$$

Based on the joint conditional density for $\left(\ln \delta_{T} / \delta_{t}\right.$, $\left.\ln H_{T} / H_{t}\right)$, we can easily show that

$$
\begin{aligned}
c_{t}( & \left.H_{t}, K, T\right)=e^{-\phi(T-t)} E_{t}\left(\left(\frac{\delta_{T}}{\delta_{t}}\right)^{-\gamma} H_{T} \mid H_{T}>K\right)-K e^{-\phi(T-t)} E_{t}\left(\left(\frac{\delta_{T}}{\delta_{t}}\right)^{-\gamma} \mid H_{T}>K\right) \\
= & H_{t} e^{-\phi(T-t)} e^{-\gamma \Psi_{\delta}(t, T)+\frac{1}{2} \gamma^{2} \Sigma_{\delta}^{2}(t, T)} e^{\Psi_{H}(t, T)+\frac{1}{2} \Sigma_{H}^{2}(t, T)-\gamma \operatorname{cov}\left(\ln \delta_{T} / \delta_{t} \ln H_{T} / H_{t}\right)} \int_{-d_{1}}^{\infty} \frac{1}{\sqrt{2 \pi}} e^{-x^{2} / 2} d x \\
& -K e^{-\phi(T-t)} e^{-\gamma \Psi_{\delta}(t, T)+\frac{1}{2} \gamma^{2} \Sigma_{\delta}^{2}(t, T)} \int_{-d_{2}}^{\infty} \frac{1}{\sqrt{2 \pi}} e^{-x^{2} / 2} d x \\
= & H_{t} \exp \left(\mu_{H}(T-t)-\rho \gamma \sigma_{H} \frac{\sigma_{\delta}}{a_{\delta}}\left(1-e^{-a_{\delta}(T-t)}\right)\right) e^{-R(t, T)(T-t)} N\left(d_{1}\right) \\
& -K e^{-R(t, T)(T-t)} N\left(d_{2}\right) \\
= & e^{-R(t, T)(T-t)} F_{t}\left(H_{t}, T\right) N\left(d_{1}\right)-K e^{-R(t, T)(T-t)} N\left(d_{2}\right),
\end{aligned}
$$


where

$$
\begin{aligned}
d_{1}= & \frac{\ln H_{t} / K+\left(\mu_{H}-\rho \gamma \sigma_{H} \frac{\sigma_{\delta}\left(1-e^{-a_{\delta}(T-t)}\right)}{a_{\delta}(T-t)}+\frac{1}{2} \sigma_{H}^{2}\right)(T-t)}{\sigma_{H} \sqrt{T-t}} \\
= & \frac{\ln F_{t}\left(H_{t}, T\right) / K+\frac{1}{2} \sigma_{H}^{2}(T-t)}{\sigma_{H} \sqrt{T-t}} \\
d_{2}= & d_{1}-\sigma_{H} \sqrt{T-t}
\end{aligned}
$$

The European put option price can be determined through the put-call parity condition since we have the value of a forward contract and the European call price.

\section{APPENDIX C}

Proof of Proposition 3.3: Risk-Neutral Valuation of Housing Index Derivatives

Proof: Under the risk-neutral approach, the value of a forward contract with a maturity $T$ and a delivery price $K$ is determined as

$$
\begin{aligned}
f_{t}^{Q}\left(H_{t}, K, T\right) & =E_{t}^{Q}\left(\exp \left(-\int_{t}^{T} r_{s} d s\right)\left(H_{T}-K\right)\right) \\
& =E_{t}^{Q}\left(\exp \left(-\int_{t}^{T} r_{s} d s\right) H_{T}\right)-K e^{-R^{Q}(t, T)(T-t)} .
\end{aligned}
$$

The conditional risk-neutral joint density for $\left(\int_{t}^{T} r_{s} d s, \ln H_{T}^{Q} / H_{t}^{Q}\right)$ is

$$
\begin{aligned}
g\left(\int_{t}^{T} r_{s} d s, \ln H_{T}^{Q} / H_{t}^{Q}\right)= & \frac{1}{2 \pi \Sigma_{r}^{Q}(t, T) \Sigma_{H}^{Q}(t, T) \sqrt{1-\tilde{\rho}^{2}}} \\
& \times \exp \frac{-1}{2\left(1-\tilde{\rho}^{2}\right)}\left[\left(\frac{\left.\int_{t}^{T} r_{s} d s-\Psi_{r}^{Q}(t, T)\right)^{2}}{\sum_{r}^{Q}(t, T)}\right)\right. \\
& -2 \tilde{\rho}_{t}^{\frac{r_{s} d s-\Psi_{r}^{Q}(t, T)}{\sum_{r}^{Q}(t, T)} \ln H_{T}^{Q} / H_{t}^{Q}-\Psi_{H}^{Q}(t, T)} \\
& \left.\left.+\left(\frac{\ln H_{T}^{Q} / H_{t}^{Q}-\Psi_{H}^{Q}(t, T)}{\sum_{H}^{Q}(t, T)}\right)^{2}\right]\right\}
\end{aligned}
$$


with

$$
\begin{aligned}
& \Psi_{H}^{Q}(t, T)=\Psi_{r}^{Q}(t, T)-\frac{1}{2} \sigma_{H}^{2}(T-t), \\
& \Psi_{r}^{Q}(t, T)=b_{r}^{Q}(T-t)+\left(r_{t}-b_{r}^{Q}\right) \frac{1-e^{-a_{r}(T-t)}}{a_{r}}, \\
& \operatorname{cov}\left(\ln H_{T}^{Q} / H_{t}^{Q}, \int_{t}^{T} r_{s} d s\right)=\sum_{r}^{Q}(t, T)^{2}+\rho_{r H} \sigma_{H} \frac{\sigma_{r}}{a_{r}}\left(T-t-\frac{1-e^{-a_{r}(T-t)}}{a_{r}}\right) . \\
& \sum_{r}^{Q}(t, T)=\frac{\sigma_{r}}{a_{r}} \sqrt{\left(1-2 \frac{1-e^{-a_{r}(T-t)}}{a_{r}(T-t)}+\frac{\left.1-e^{-2 a_{r}(T-t)}\right)(T-t)}{2 a_{r}(T-t)},\right.} \\
& \tilde{\rho}=\frac{\operatorname{cov}\left(\ln H_{T}^{Q} / H_{t}^{Q}, \int_{t}^{T} r_{s} d s\right)}{\sum_{r}^{Q}(t, T) \Sigma_{H}(t, T)}, \\
& \sum_{\bar{H}}^{Q}(t, T)=\sqrt{\sigma_{H}^{2}(T-t)+2 \rho_{r H} \sigma_{H} \frac{\sigma_{r}}{a_{r}}\left(T-t-\frac{1-e^{-a_{r}(T-t)}}{a_{r}}\right)+\sum_{r}^{Q}(t, T)^{2}} .
\end{aligned}
$$

Therefore, the value of a forward contract is computed as

$$
\begin{aligned}
f_{t}^{Q}\left(H_{t}, K, T\right) & =E_{t}^{Q}\left(\exp \left(-\int_{t}^{T} r_{s} d s\right) H_{T}\right)-K e^{-R(t, T)(T-t)} \\
& =H_{t} e^{-\Psi_{r}^{Q}(t, T)+\frac{1}{2} \Sigma_{r}^{Q}(t, T)^{2}} e^{\Psi_{H}^{Q}(t, T)+\frac{1}{2} \sum_{H}^{Q}(t, T)^{2}-\operatorname{cov}\left(\int_{t}^{T} r_{s} d s, \ln H_{T}^{Q} / H_{t}^{Q}\right)}-K e^{-R(t, T)(T-t)} \\
& =H_{t}-K e^{-R(t, T)(T-t)} .
\end{aligned}
$$

At the initiation, we set the forward price to be the delivery price so that the value of the forward contract is zero. That is, the forward price is

$$
F_{t}^{Q}\left(H_{t}, T\right)=K=H_{t} e^{-R(t, T)(T-t)} .
$$

Consider a European call option with a maturity $T$ and a strike price $K$ on the housing index. The risk-neutral value of this call is priced as follows:

$$
c_{t}^{\mathcal{Q}}\left(H_{t}, K, T\right)=E_{t}^{\mathcal{Q}}\left(\exp \left(-\int_{t}^{T} r_{s} d s\right) \times \max \left(H_{T}-K, 0\right)\right) .
$$

Using the joint conditional density for $\left(\int_{t}^{T} r_{s} d s, \ln H_{T}^{Q} / H_{t}^{Q}\right)$, we can easily
show that 


$$
\begin{aligned}
c_{t}^{Q} & \left(H_{t}, K, T\right) \\
= & E_{t}^{Q}\left(\exp \left(-\int_{t}^{T} r_{s} d s\right) H_{T} \mid H_{T}>K\right)-K E_{t}^{Q}\left(\exp \left(-\int_{t}^{T} r_{s} d s\right) \mid H_{T}>K\right) \\
= & H_{t} e^{-\Psi_{r}^{Q}(t, T)+\frac{1}{2} \Sigma_{r}^{Q}(t, T)^{2}} e^{\Psi_{H}^{Q}(t, T)+\frac{1}{2} \Sigma_{H}^{Q}(t, T)^{2}-\operatorname{cov}\left(\int_{t}^{T} r_{s} d s, \ln H_{T}^{Q} / H_{t}^{Q}\right)} \int_{-d_{1}^{Q}}^{\infty} \frac{1}{\sqrt{2 \pi}} e^{-x^{2} / 2} d x \\
& -K e^{-\Psi_{r}^{Q}(t, T)+\frac{1}{2} \Sigma_{r}^{Q}(t, T)^{2}} \int_{-d_{2}^{Q}}^{\infty} \frac{1}{\sqrt{2 \pi}} e^{-x^{2} / 2} d x \\
= & H_{t} N\left(d_{1}^{Q}\right)-K e^{-R(t, T)(T-t)} N\left(d_{2}^{Q}\right)
\end{aligned}
$$

where

$$
d_{1}^{Q}=\frac{\ln H_{t} / K+R(t, T)(T-t)+\frac{1}{2} \Sigma_{H}^{Q}(t, T)^{2}}{\Sigma_{H}^{Q}(t, T)} \text { and } d_{2}^{Q}=d_{1}^{Q}-\sum_{H}^{Q} \sigma_{H}(t, T) .
$$

Again, given the risk-neutral value of a forward contract and the price for a European call, we can determine a European put option price through the put-call parity condition.

\section{BIBLIOGRAPHY}

Black, F., \& Scholes, M. (1973). The pricing of options and corporate liabilities. Journal of Political Economy, 81, 637-655.

Case, K. E. (1986). The market for single-family homes in Boston, 1979-1985. New England Economic Review, May/June, 38-48.

Cauley, S. D., Pavlov, A. D., \& Schwartz, E. S. (2007). Homeownership as a constraint on asset allocation. Journal of Real Estate Finance and Economics, 34, 283-311.

Chan, K. C., Karolyi, A., Longstaff, F. A., \& Sanders, A. B. (1992). The volatility of short-term interest rates: An empirical comparison of alternative models of the term structure of interest rates. Journal of Finance, 47, 1209-1227.

Cooper, D., \& Ng, S. (2008). Collateralized borrowing: Illiquid assets and households' precautionary savings motive, University of Michigan.

Lucas, R. E. (1978). Asset prices in an exchange economy. Econometrica, 46, $1429-1445$.

Marsh, T. A., \& Merton, R. (1987). Dividend behavior for the aggregate stock market. Journal of Business, 60, 1-40.

Milevsky, M. A. (2004). Risk for sale. Advisor's Edge, Mid-October, 18-23.

Quigley, J. M. (2006). Real estate portfolio allocation: The European consumers' perspective. Journal of Housing Economics, 15, 169-188.

Shiller, R. J. (2008). Derivatives marketed for home prices. Cowles Foundation Discussion Paper No. 1648.

Vasicek, O. (1977). An equilibrium characterization of the term structure. Journal of Financial Economics, 5, 177-188. 